\title{
Multifocal motor neuropathy with conduction block: a study of 24 patients
}

Pierre Bouche, Antoine Moulonguet, Amena Ben Younes-Chennoufi, David Adams, Nicole Baumann, Vincent Meininger, Jean-Marc Léger, Gérard Said

\begin{abstract}
Twenty four patients with pure motor neuropathy are reported. The chronic motor involvement associated with fasciculations and cramps, mainly in the arms, led, in most patients, to an initial diagnosis of motor neuron disease. In some patients (nine of 24 ), there was no appreciable muscle atrophy. Tendon reflexes were often absent or weak. The finding of persistent multifocal conduction block confined to motor nerve fibres raises questions about the nature and the importance of this syndrome. Segmental reduction of motor conduction velocity occurred at the site of the block, but significant slowing of motor nerve conduction was not found outside this site. The response to intravenous IVIg treatment seems to be correlated with the absence of amyotrophy. Patients with little or no amyotrophy had an initial and sustained response to IVIg, and did not develop amyotrophy during the follow up study. They could be considered to have a variant of chronic inflammatory demyelinating polyneuropathy. Patients with pronounced amyotrophy independent of the disease duration did not respond as well to IVIg treatment, suggesting the existence of a distinct entity. Among the patients treated about two thirds who had an initial good response to IVIg had high or significant antiganglioside GM1 (antiGM1) antibody titres, but there was no correlation between the high titres before treatment and long lasting response to IVIg treatment.
\end{abstract}

(F Neurol Neurosurg Psychiatry 1995;59:38-44)

Keywords: motor neuropathy; conduction block; antiGM1 antibodies; immunoglobulin treatment

Since the description, by Lewis et al in 1982," of a multifocal chronic sensory-motor peripheral neuropathy with persistent conduction blocks, pure multifocal motor neuropathy with persistent conduction blocks has been widely reported. ${ }^{2-12}$ The patients have multiple mononeuropathy with purely motor manifestations. There is asymmetric weakness with various degrees of amyotrophy, cramps, fasciculations, and preserved or abolished tendon reflexes. Most patients were initially diagnosed as having motor neuron disease. In some cases, the presence of a high serum anti-
GM1 antibody titre ${ }^{510^{13-19}}$ and the response to immunosuppressive treatment ${ }^{20-26}$ suggested an immunopathological mechanism. This was supported by the fact that anti-GM1 antibodies bind at the node of Ranvier, ${ }^{27}$ and that demyelination occurs at the site of the conduction block. ${ }^{28}$

Although some authors ${ }^{29}$ suggest that multifocal motor neuropathy may be a variant of a chronic inflammatory demyelinating polyneuropathy, many questions persist concerning the nature of the underlying process, the natural history, the homogeneity of the syndrome, ${ }^{19}{ }^{30-33}$ and its response to treatment. We report here the clinical, electrophysiological, histological, and biological findings and response to treatment in 24 patients with pure multifocal motor neuropathy and persistent conduction block.

\section{Patients and methods}

PATIENTS

Most patients were referred with a diagnosis of motor neuron disease, although they lacked signs of upper motor neuron or bulbar involvement. Patients were considered to have multifocal motor neuropathy if they had had progressive weakness in at least one limb for at least six months without sensory loss, and multifocal conduction block in at least two nerves.

\section{CLINICAL EXAMINATIONS}

The patients were assessed using: (a) the Medical Research Council (MRC) rating scale for muscle strength; five muscle groups corresponding to proximal and distal upper and lower limbs were examined and tested according to the MRC scale. (b) A modified Rankin disability scale: $0=$ asymptomatic; $1=$ non-disabling symptoms that do not interfere with lifestyle; $2=$ minor disability symptoms that lead to some restriction to lifestyle, but do not interfere with the patients' capacity to look after themselves; 3 = moderate disability symptoms that significantly interfere with lifestyle or prevent totally independent existence; $4=$ moderately severe disability symptoms that clearly prevent independent existence although the patient does not need constant attention day and night; $5=$ severely disabled, totally dependent, requiring constant attention day and night.

ELECTRODIAGNOSTIC STUDIES

Electrodiagnostic studies were performed with a Viking Nicolet electromyograph. and in final revised form

16 March 1995.

Accepted 16th March 1995 
Table 1 Summary of techniques $A$ and $B$ for anti-GM1 antibody determination in human serum by enzyme linked immunosorbent assay (ELISA)

\begin{tabular}{lll}
\hline & Technique $A$ & Technique B \\
\hline Plates & Polystyrene (Dynatech) & Immulon (Dynatech) \\
GM1 for coating & GM1 (Fidia) 1 mg & GM1 (Fidia) 0.5 mg \\
Blocking solution & PBS + 0.05\% Tween 20 & PBS + 1\% BSA \\
Blocking duration & $30 \mathrm{~min}$ & $6 \mathrm{~h}$ overnight \\
Blocking temperature & RT & RT $+4^{\circ} \mathrm{C}$ \\
Test serum dilution & $1: 20$ & $1: 100$ \\
Incubation time & $2 \mathrm{~h}$ & overnight \\
with test serum & $4^{\circ} \mathrm{C}$ & $4^{\circ} \mathrm{C}$ \\
Incubation temperature & PBS + Tween 20 & PBS \\
Washing solution & Goat & Goat \\
Secondary antibody (SA) & HRP & HRP \\
IgG or IgM & $2 \mathrm{~h}$ & $1 \mathrm{~h}$ \\
Incubation time with SA & $4^{\circ} \mathrm{C}$ & RT \\
Incubation temperature & OPD & OPD \\
Substrate & &
\end{tabular}

BSA = bovine serum albumin; $\mathrm{PBS}=$ phosphate buffered saline; $\mathrm{RT}=$ room temperature $; \mathrm{HRP}$ $=$ horseradish peroxidase conjugate; $\mathrm{OPD}=\sigma$-phenylene diamine.
Needle EMG examination was performed in all patients. The incidence of spontaneous activity at rest (fibrillation potentials and positive sharp waves) was recorded. The size of motor unit potentials (MUPs) and the pattern of recruitment during maximal effort were also analysed.

Motor nerve conduction studies were performed with supramaximal percutaneous nerve stimulation, whereas compound muscle action potentials (CMAPs) were recorded with surface electrodes. For all patients, median, ulnar, and peroneal nerves were examined on both sides. The median nerve was stimulated at the wrist, elbow, axilla, and Erb's point. The ulnar nerve was stimulated at the wrist, below and above the elbow, on the axilla, and at Erb's point. At Erb's point, the nerve was stimulated with monopolar electrodes. We did not systematically search for conduction block in the radial nerve, as this was considered unreliable. The peroneal nerve was stimulated at the ankle, below and above the fibular head. For all nerve conduction studies skin temperature was maintained at $36^{\circ} \mathrm{C}$. Distal latencies, conduction velocity, evoked motor response amplitudes (baseline to negative peak), and areas under the negative phase and its duration were measured. In upper limbs, the nerves were stimulated at five sites, corresponding to four segments. No segments exceeded $25 \mathrm{~cm}$ in length. Variation in the proximal/distal amplitude and area ratio and conduction velocity were measured for each segment. Latencies for $F$ waves were measured after distal supramaximal stimulation (at least 16 stimuli) in the median, ulnar, and peroneal nerves.

Sensory nerve conduction and amplitude were measured in the median, ulnar, superficial peroneal, and sural nerves with surface recording and stimulating electrodes. The nerves were stimulated by orthodromic techniques in the upper limbs and antidromic techniques in the lower limbs. Amplitudes were measured peak to peak.

To determine if the reduction in amplitude was due to conduction block, or temporal dispersion, or both, we analysed the amplitude, area, and duration of the negative phase of the CMAP elicited from each site of stimulation. Between Erb's point and the axilla, a loss of $50 \%$ of the CMAP amplitude and area after proximal stimulation suggested a possible partial conduction block. More distally a loss of $30 \%$ was considered sufficient to confirm the block. The reduction of CMAP amplitude was considered to be due to temporal dispersion if the duration of the CMAP increased by more than $30 \%$ and the corresponding loss of area did not exceed $50 \%$. The amplitude and area changes occurred abruptly over each nerve segment rather than as gradual losses along the length of the nerve.

\section{HISTOLOGICAL EXAMINATIONS}

Morphological examination of a sensory nerve (radial cutaneous), including teased fibre studies, was performed in 12 patients under local anaesthesia. The nerve specimens were fixed in $3.6 \%$ glutaraldehyde. The fragments were postfixed in osmium tetroxide. One nerve fragment was studied by teasing the endoneurial content. Another was embedded in epon and thionin stained $1 \mu$ thick sections were examined.

\section{BIOLOGICAL EXAMINATIONS}

Serum enzymes and conventional biological variables were assayed. Protein immunoelectrophoresis was performed and CSF was examined. In all cases, the patients were sampled before immunosuppressive treatment. Anti-GM1 antibody titres were measured by enzyme linked immunosorbent assay (ELISA) according to two techniques previously described. ${ }^{1834}$ Table 1 summarises these and they have been evaluated previously. ${ }^{35}$ The results of the assays were expressed differently. In technique $A$, serum was considered to contain anti-GM1 antibodies when, at a 1:20 dilution, the optical density (OD) was more than 2 SD above the mean obtained with 10 internal standards (ODX). The titre was defined as the reciprocal of the serum dilution required to obtain the ODX. Thus in technique $A$, a titre $\geqslant 20$ was considered to be significant $(+)$ and a titre $\geqslant 100$ was considered to be high $(++)$. In technique $B$, serum was considered to contain anti-GM1 antibodies when, at a 1:100 dilution, the optical density was three times the mean of the normal controls at the same dilution. As reported by Sadiq et $a l,{ }^{17}$ anti-GM1 antibodies were found in normal serum up to a 1:400 dilution. The titre was considered significant $(+)$ when antibodies were detected at 1:800 dilution, and high $(++)$ when detected at $\geqslant 1: 3200$. In technique $B$, all positive cases were confirmed by immunodetection on thin layer chromatography as described by Mailly et $a l^{36}$ with serum at a 1:100 dilution. When positivity was not confirmed by thin layer chromatography the sample was considered to be negative. Controls consisted of patients with chronic inflammatory demyelinating polyneuropathy and normal subjects of the same age groups. 
Table 2 Clinical characteristics

\begin{tabular}{|c|c|c|c|}
\hline & $\begin{array}{l}\text { All patients } \\
(n=24)\end{array}$ & $\begin{array}{l}\text { Group 1 } \\
(n=15)\end{array}$ & $\begin{array}{l}\text { Group } 2 \\
(n=9)\end{array}$ \\
\hline Sex ratio $M / F$ & $20 / 4$ & $14 / 1$ & $6 / 3$ \\
\hline Age at onset (y) (mean (SD)) & $49 \cdot 8(9 \cdot 5)$ & $50 \cdot 3(8 \cdot 8)$ & $47 \cdot 3(11 \cdot 2)$ \\
\hline Disease duration (y) (mean (SD)) & $9 \cdot 2(6 \cdot 3)$ & $12.06(6 \cdot 8)$ & $6 \cdot 7(2 \cdot 6)^{\star}$ \\
\hline \multicolumn{4}{|l|}{ Limb onset (No of patients): } \\
\hline Upper & 21 & 13 & 8 \\
\hline Lower & 3 & 2 & 1 \\
\hline Cramp (No of cases) & 14 & 9 & 5 \\
\hline Fasciculation (No of cases) & 17 & 11 & 6 \\
\hline Myokymia (No of cases) & 2 & 1 & 1 \\
\hline \multicolumn{4}{|l|}{ Tendon reflex (No of cases): } \\
\hline Normal & 6 & 3 & 3 \\
\hline Absent or weak & 17 & 12 & 5 \\
\hline Brisk & 1 & - & 1 \\
\hline
\end{tabular}

Group 1 = patients with amyotrophy; group 2 = patients without amyotrophy.

$\star P<0.05$, group $1 v$ group 2 .

\section{Results}

CLINICAL CHARACTERISTICS (TABLE 2)

Twenty four patients, 20 men and four women, were selected on the basis of persistent multifocal conduction blocks in motor fibres. The mean age (SD, range) at onset of symptoms was $49.8(9.5,32-70)$ years. The mean duration of the disease was $9 \cdot 2(6 \cdot 3$, 3-28) years.

Onset occurred in one distal upper limb in 21 of 24 patients. In three patients, onset was unilateral in the lower limbs. There were no particular circumstances surrounding the onset, except in two patients with proximal pain in an upper limb. Painful cramps were a usual complaint in 14 of 24 patients. There were no sensory symptoms and the motor deficit was isolated. The disease usually had a very slow progression.

When the deficit was fully developed, upper limb involvement was present in all patients: motor weakness was distal and unilateral in nine patients, distal and bilateral in 13, and affected the proximal and distal parts of the limbs in two patients. In the lower limbs, motor weakness, when it occurred (in 12 cases), was always distal and was unilateral in six cases. The motor deficit therefore affected the distal muscles in the median and ulnar distribution in the upper limbs, although in one third of patients, the deficit mainly affected the wrist and finger extensors in a radial distribution. In six patients, the motor deficit was limited to one upper limb, without amyotrophy in five. Overt muscle atrophy was present in 15 of 24 patients and was usually located at the site of maximal motor deficit. In nine patients no appreciable muscle atrophy was found. One of them with radial motor weakness had hypertrophy of the extensor carpi radialis longus and brevis. A significant difference in the duration of the disease occurred in these two categories of patients: in patients with amyotrophy the mean duration was 12 (SD 6.7) years $v 6.6$ (SD 2.5) years in the non-atrophied group $(P=0.033)$. In the first group the onset of amyotrophy always appeared during the first year of evolution.

Fasciculations were seen in 17 of 24 patients, usually in the involved limb, whereas myokymia occurred in only two patients. The tendon reflexes were weak or abolished in the involved territories in 17 of 24 patients. They were brisk without Babinski's sign in only one patient, who spontaneously improved and whose deficit was localised in the right distal upper limb.

\section{ELECTROPHYSIOLOGICAL CHARACTERISTICS}

In the upper limbs, conduction blocks were found at proximal sites between Erb's point and the axilla, at intermediate sites between axilla and elbow, and at distal sites below the elbow. In lower limbs, the conduction blocks were located only below or in the area of the fibular head on the peroneal nerve. Conduction blocks were always found in the upper limbs. In the lower limbs conduction blocks were only found in six patients. The location of conduction blocks was similar in both nerves and there were no predominant sites in the distribution of the conduction blocks. In all cases, the degree of the conduction block exceeded $50 \%$, which excluded a reduction of the CMAP area due to an interphase cancellation. ${ }^{37}$ Motor nerve conduction velocities were usually normal outside the site of the blocked segments. Across the blocked segments, the motor conduction velocity was sometimes greatly reduced. In one patient, a pronounced slowing of proximal conduction without associated conduction block was initially found, but distal amplitude was very low. After IVIg treatment, an improvement in distal CMAP amplitude was found and a proximal conduction block could therefore be demonstrated. Motor distal latencies were slightly prolonged in most patients: for the median nerve, 19 of 24 patients had latencies of more than 3.6 (mean (SD) $4.2(0.7)$ ) ms; for the ulnar nerve, 15 of 24 patients had latencies of more than 3 (mean $3.5(0.9)$ ) ms; for the peroneal nerve, and 12 of 24 had latencies of more than 5 (mean $5.3(1 \cdot 1)$ ) ms.

Distal CMAPs were considerably reduced in some blocked nerves, although in other blocked nerves in the same patient they were normal. In most patients, the reduction in CMAP amplitude was correlated with the degree of muscle atrophy. In a few patients however, despite some degree of clinical atrophy, the reduction in CMAP amplitude was less than expected. In the case of a large reduction in distal CMAP amplitude (less than 1 mv), conduction block was mostly difficult to demonstrate. Only one patient had normal F wave latencies in all nerves. Some patients had normal $F$ wave latencies even in the presence of blocks, but a prolonged or absent $F$ wave latency was found in at least one of the nerves examined. In some patients, an $\mathrm{F}$ wave was not obtained or its latency was prolonged even in the absence of conduction blocks. In nine cases, an intermediate wave with electrophysiological characteristics of an axonal reflex was found in the upper limbs: in the median nerve in four patients, in the ulnar nerve in three patients and in both nerves in two patients.

Sensory potential was usually normal or slightly altered: in the median nerve, it was below $15 \mu \mathrm{v}$ in eight of 21 patients (mean 23.5 (SD 17.1) $\mu \mathrm{v}$ ); in the ulnar nerve, it was 
Table 3 Biological and histological characteristics

\begin{tabular}{|c|c|c|c|}
\hline & $\begin{array}{l}\text { All patients } \\
(n=24)\end{array}$ & $\begin{array}{l}\text { Group 1 } \\
(n=15)\end{array}$ & $\begin{array}{l}\text { Group 2 } \\
(n=9)\end{array}$ \\
\hline \multicolumn{4}{|l|}{ Serum immunoelectrophoresis $(23 / 24)$ : } \\
\hline Normal & 17 & 11 & 6 \\
\hline Polyclonal gammapathy & 5 & 3 & 2 \\
\hline Hypogammaglobulinaemia & 1 & & 1 \\
\hline \multicolumn{4}{|c|}{ Serum anti-GM1 IgM activity (technique A) $(24 / 24)$ : } \\
\hline Negative $<20$ & 7 & 3 & 4 \\
\hline Significant $\geqslant 20$ & 7 & 5 & 2 \\
\hline High titres $\geqslant 100$ & 10 & 7 & 3 \\
\hline \multicolumn{4}{|c|}{ Serum anti-GM1 IgM activity (technique B) $(23 / 24)$ : } \\
\hline Negative or low titres & 11 & 7 & 4 \\
\hline Significant $\geqslant 1: 800$ & 4 & 2 & 2 \\
\hline High titres $\geqslant 1: 3,200$ & 8 & $\overline{6}$ & $\overline{2}$ \\
\hline \multicolumn{4}{|l|}{ Nerve biopsy (12/24): } \\
\hline Normal & 5 & 3 & 2 \\
\hline Clusters & 4 & 1 & 3 \\
\hline Demyelination and remyelination & 2 & 1 & 1 \\
\hline Active axonal lesion + clusters & 1 & - & 1 \\
\hline
\end{tabular}

Group 1 = patients with amyotrophy; group 2 = patients without amyotrophy.

below $10 \mu \mathrm{v}$ in nine of 21 patients (mean $12 \cdot 2$ (SD 7.9) $\mu \mathrm{v}$ ); in peroneal nerve it was below $10 \mu \mathrm{v}$ in five of 22 patients (mean 17.6 (SD 11.7) $\mu \mathrm{v})$.

Needle EMG showed fibrillation potentials in distal muscles in five of 20 patients in the upper limbs and in six of 24 patients in the lower limbs. The interference pattern was reduced but no giant units were detected.

LABORATORY EXAMINATIONS (TABLE 3)

The CSF was examined in 19 of 24 patients, and was normal in all. Serum immunoelectrophoresis was performed in 23 of 24 patients; no monoclonal peaks were found. A polyclonal profile was found in five patients (three IgM, two IgG), one patient had hypogammaglobulinaemia. The other biological variables were normal.

\section{ANTI-GM1 ANTIBODIES}

Table 3 summarises anti-GM1 antibody titres. All the significant or high antibody titres were of the IgM class. In one patient,
anti-GM1 antibodies were not titred with technique $B$. When examined with technique A, 10 of 24 patients (42\%) and eight of 23 (35\%) with technique $B$ had high titres. With technique A seven of $24(29 \%)$ and with technique $B$ four of $23(17 \%)$ had significant titres. Thus with technique A, 17 of 24 (71\%) of the patients and with technique B 12 of 23 $(52 \%)$ had significant or high antibody titres. Assayed by technique A, $17 \cdot 5 \%$ normal subjects had low levels of anti-GM1 antibodies. By technique $B$, they were excluded as the titres were always below or equal to $1: 400 .^{18}$ With both techniques, $13 \%$ of patients with CIDP without conduction blocks had low but significant anti-GM1 antibody titres.

NERVE BIOPSIES (TABLE 3)

Twelve patients had nerve biopsies. In five patients, no abnormalities were detected. In four patients, the density of nerve fibres was preserved, and there were no abnormalities on teased fibre preparations, but several clusters of regenerating fibres were present on semithin sections (figure). In one patient, we found signs of active axonal lesions in one fascicle associated with regeneration in other fascicles (clusters). In two patients, signs of demyelination and remyelination on teased fibre preparations and semithin sections were seen for a few fibres.

\section{TREATMENT (TABLES 4 AND 5)}

Five patients were not treated. The other 19 had IVIg $(0.4 \mathrm{~g} / \mathrm{kg} /$ day during five days every month for at least six months). All patients have been followed up for at least two years and were evaluated every three months. IVIg was repeated every two or three months if there was improvement at the end of the six month period. Improvement was correlated with at least a one point gain in muscle strength (MRC scale), and one point gain in
Cross section $(1 \mu)$ of a biopsy specimen of the superficial radial nerve from a patient with motor neuropathy and multifocal conduction block. The density of nerve fibres is normal. Several clusters (arrows) of small regenerating fibres are present, indicating that lesions of axons have occurred proximally, likely at the site of conduction block. Thionin staining, $b a r=10 \mu \mathrm{m}$.

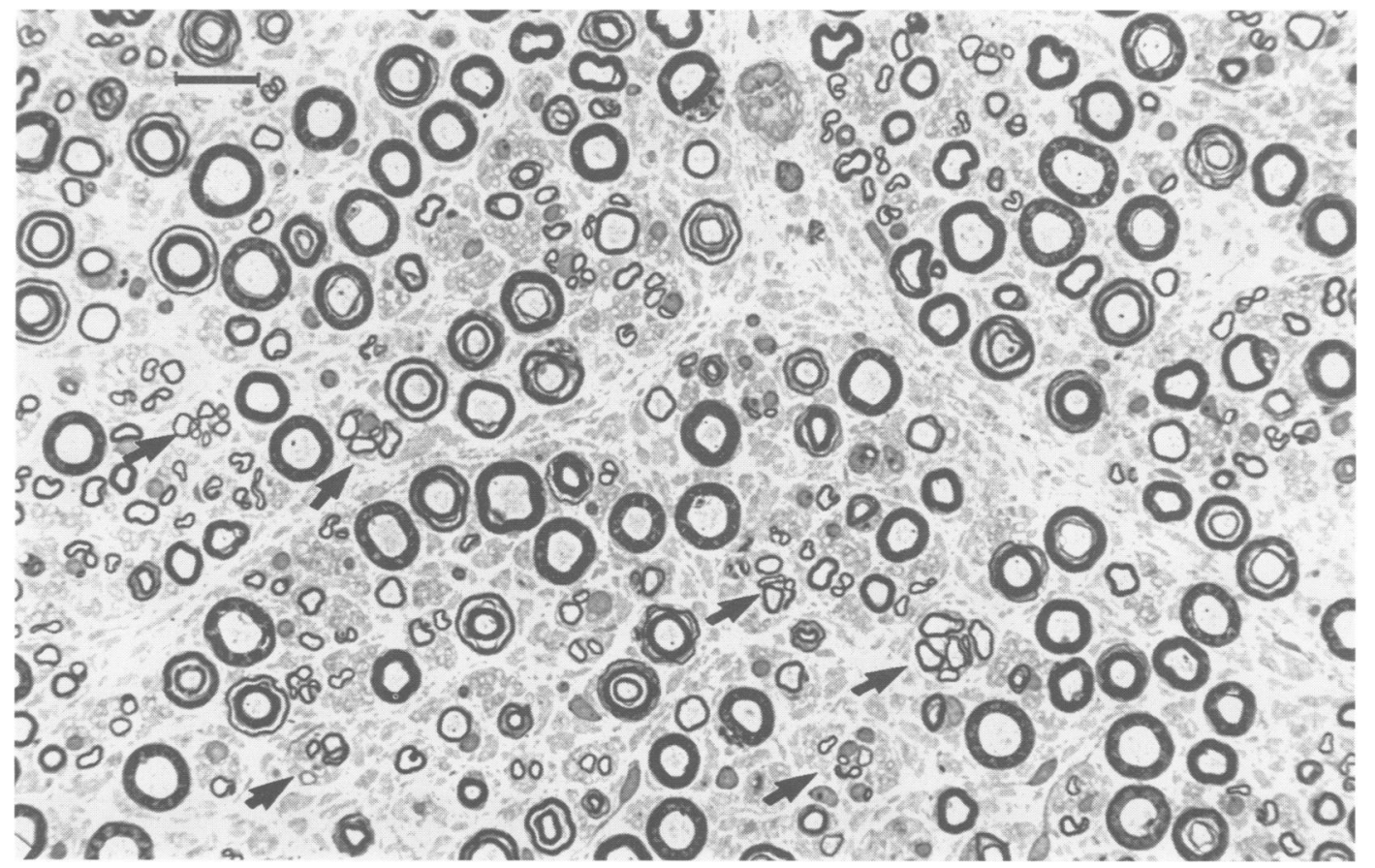


Table 4 Response to treatment

\begin{tabular}{|c|c|c|c|}
\hline & $\begin{array}{l}\text { All patients } \\
(n=24)\end{array}$ & $\begin{array}{l}\text { Group 1 } \\
(n=15)\end{array}$ & $\begin{array}{l}\text { Group 2 } \\
(n=9)\end{array}$ \\
\hline \multicolumn{4}{|l|}{ Treatment: } \\
\hline None & 5 & 2 & 3 \\
\hline Intravenous IVIg & 19 & 13 & 6 \\
\hline \multicolumn{4}{|c|}{ Response to IVIg treatment $(19 / 24)$ : } \\
\hline Absent & 2 & 2 & - \\
\hline Transient & 11 & 10 & 1 \\
\hline Sustained & 6 & 1 & 5 \\
\hline \multicolumn{4}{|l|}{ Follow up study: } \\
\hline \multicolumn{4}{|l|}{ Without treatment: } \\
\hline Improvement & 1 & - & 1 \\
\hline Stabilisation & 4 & 2 & 2 \\
\hline \multicolumn{4}{|l|}{ IVIg treatment: } \\
\hline Improvement & 6 & 1 & 5 \\
\hline Stabilisation & 12 & 12 & - \\
\hline Worsened & 1 & - & 1 \\
\hline
\end{tabular}

Group 1 = patients with amyotrophy; group 2 = patients without amyotrophy; transient = transient response to IVIg lasting no longer than six months; sustained = response to IVIg lasting longer than six months; follow up study = follow-up study after six months (mean duration = three years). ated with an initial good response to IVIg. Four patients with technique $\mathrm{A}$ and five with technique $B$ with an initially good clinical response had low or negative values (one of the 17 patients who initially responded to IVIg was not titred with technique B). One of the patients who did not respond to the IVIg treatment had no anti-GM1 antibodies with both techniques, and the other had significant titres with technique A only. Of the five patients who were not treated, one improved spontaneously and had negative titres. Among the four others, who all stabilised, three had high or significant titres with technique $A$ and one with technique $B$. Of the 19 treated patients, during the follow up study six improved, four had high or significant titres with technique $\mathrm{A}$ and five with technique $\mathrm{B}$. Twelve stabilised, nine had high or significant titres with technique $A$ and six with technique B. Therefore, of the 18 patients who stabilised or improved with IVIg treatment, $13(72 \%)$ had high or significant titres with technique $\mathrm{A}$ or technique B. The patient who worsened had high titres with technique $\mathrm{A}$. the first infusion. Five of them who had no muscle atrophy, had a one to two point gain on the MRC scale and two points or more on the functional activity scale, which persisted after six months. They were essentially those with radial involvement. Some of them totally recovered their wrist extension. The last one, with muscle atrophy, had a two point gain on the functional activity scale. The others (11 patients) had a good initial response that did not last more than six months. Most patients showed a dramatic change in their daily living due to improved hand skill only during the first IVIg treatments, although the MRC scale did not show significant variation. Ten of the 11 patients with a transient response to IVIg treatment had pronounced distal upper limb amyotrophy. In the group of patients who had long term improvement, repetition of the treatment did not have the same response. Nevertheless, motor weakness remained better than their original state. Of the 19 treated patients who had significant or high antiGM1 antibodies (13 (68\%) with technique A and $11(58 \%)$ with technique B) were associ-

\section{Discussion}

We have studied 24 patients with a pure motor syndrome resulting from persistent multifocal conduction blocks. Some patients had minor sensory symptoms, such as shoulder pain or slight distal paraesthesiae, but none had sensory loss. Tendon reflexes were normal, decreased, or abolished in all cases but one. There were no signs of upper motor neuron involvement or bulbar signs. In most, onset was in the distal upper limbs, usually asymmetrically. Upper limbs were always affected. Onset was always insidious, although in two patients it was preceded by proximal pain in the upper limbs. The syndrome usually progressed over several years. In some patients there was a clear multifocal pattern affecting several limbs, primarily distally. In others, the distribution was more confined to one limb, mimicking the motor involvement seen at the onset of motor neuron disease. The pattern of muscle wasting varied. In some patients it was pronounced, whereas in others

Table 5 Response to treatment in relation to the titre of anti-GM1 activity

\begin{tabular}{|c|c|c|c|c|c|}
\hline & \multirow[b]{2}{*}{$\begin{array}{l}\text { All patients } \\
n=24\end{array}$} & \multicolumn{2}{|l|}{ High titres } & \multicolumn{2}{|c|}{ Significant titres } \\
\hline & & $\begin{array}{l}\text { Technique } A \\
n=24\end{array}$ & $\begin{array}{l}\text { Technique } B \\
n=23\end{array}$ & $\begin{array}{l}\text { Technique } A \\
n=24\end{array}$ & $\begin{array}{l}\text { Technique } B \\
n=23\end{array}$ \\
\hline \multicolumn{6}{|l|}{ Treatment: } \\
\hline None & 5 & 1 & 1 & 2 & - \\
\hline Intravenous IVIg & 19 & 9 & 7 & 5 & 4 \\
\hline \multicolumn{6}{|c|}{ Response to IVIg treatment $(19 / 24)$ : } \\
\hline Absent & 2 & - & - & 1 & $\bar{a}$ \\
\hline Transient & 11 & 6 & 4 & 3 & 2 \\
\hline Sustained & 6 & 3 & 3 & 1 & 2 \\
\hline \multicolumn{6}{|l|}{ Follow-up study: } \\
\hline \multicolumn{6}{|l|}{ Without treatment: } \\
\hline Improvement & 1 & - & - & - & - \\
\hline Stabilisation & 4 & 1 & 1 & 2 & - \\
\hline \multicolumn{6}{|l|}{ IVIg treatment: } \\
\hline Improvement & 6 & 3 & 3 & 1 & 2 \\
\hline Stable & 12 & 5 & 4 & 4 & 4 \\
\hline Worsened & 1 & 1 & - & - & - \\
\hline
\end{tabular}

Transient = transient response to IVIg lasting no longer than six months; sustained = response to IVIg lasting longer than six months; follow-up study $=$ follow-up study after six months (mean duration $=$ three years). 
it was absent, even after five years of evolution. It was, therefore, possible to distinguish two groups of patients according to the presence or absence of muscle atrophy. The duration of the disease was significantly longer in the patients with atrophy, although the amyotrophy did not depend on the duration. The amyotrophy was always present during the first year of the disease. Cramps and fasciculations were present in most patients, mainly at the onset of the symptoms.

Motor involvement usually interfered with daily living, but in most cases, less than expected from the intensity of the motor deficit and wasting. Patients did not have the same pattern of evolution: most, after an initial worsening, were stable, and motor involvement did not show the progression usually found in motor neuron disease. A few patients progressively worsened. One patient improved spontaneously.

Conduction blocks were found constantly in the upper limbs in all patients. These were usually multifocal with no site predominance, although in three patients who presented with monomelic upper limb involvement, conduction blocks were located proximally. In some cases, conduction blocks occurred without corresponding clinical motor deficit in the nerve territory, although in most of the patients there was a good correlation between conduction block and motor deficit.

A segmental reduction of motor nerve conduction velocity was found at the sites of blocks, contrasting, in proximal blocks, with normal or slightly reduced distal velocities, except in one case. It is difficult, however, to interpret the importance of the conduction failure because the type and size of fibres in which conduction velocity was measured were not the same. Conduction velocities through, and distal to, the site of block cannot therefore be compared.

$F$ waves were altered in most of the nerves with conduction blocks, as already reported. ${ }^{9}$ Abnormal $\mathrm{F}$ waves in the absence of conduction blocks suggest more proximal involvement. In these patients, spinal cervical stimulation is thought to be helpful, ${ }^{9}$ but not in the six patients in whom it was performed in our series. In patients with motor neuron disease, $\mathrm{F}$ waves are never altered to the same degree. $^{38}$ Altogether, alteration of $F$ waves seemed to be a reliable electrophysiological variable in this type of neuropathy.

Multifocal motor neuropathies are therefore in almost all cases associated with conduction blocks and segmental reduction of conduction velocity. In some cases, slowing of segmental conduction may precede the detection of a conduction block, as in one of our cases. It is more than likely that patients with multifocal motor neuropathy with segmental conduction slowing can be grouped together with patients with persistent conduction block.

In some patients an intermediate late response was found, which was considered to be an axon reflex. ${ }^{39}$ This response is never found in motor neuron disease, but occurs occasionally in patients with multifocal motor neuropathy and persistent conduction block. ${ }^{2}$

In some patients, we found a slight alteration of the SNAPs in the nerves tested, with or without motor conduction block, despite normal clinical examination of the different sensory modalities.

Minor abnormalities on biopsy specimens of the superficial radial nerve showed that sensory fibres were not completely spared. But these abnormalities were not predictive for response to immunosuppressive treatment as was reported by Sahenk et al. ${ }^{40}$ In a few cases, subclinical involvement of sensory nerves was detected by electrophysiological examination. The slight electrophysiological abnormalities of SNAPs and the moderate morphological modifications of the radial cutaneous nerve in some patients could indicate that there is a continuum between purely motor neuropathies with conduction block and the sensory-motor neuropathies with conduction block of the type reported by Lewis et al. ${ }^{1}$ Abnormal sensory potentials have also been described in motor neuron disease. ${ }^{41}{ }^{42}$

We found high titres of anti-GM1 antibodies in $42 \%$ of patients with technique $A$ and $35 \%$ with technique $B$ and in none of the control groups with CIDP or normal controls, confirming the specificity of high titres of antiGM1 antibodies in this group. ${ }^{34}{ }^{43}$ When using technique $\mathrm{A}$ and technique $\mathrm{B}$, respectively $29 \%$ and $48 \%$ of the patients examined had no significant or detectable titres of anti-GM1 antibodies. It is known, however, that other autoantibodies can be found in this pathology and these should be assayed. In a previous study, Ben Younes-Chennoufi et al ${ }^{18}$ found IgM reactivity against other glycolipids. The patients without anti-GM1 antibodies nevertheless had the typical clinical and electrophysiological features of multifocal motor neuropathy. Low concentrations of anti-GM1 antibodies, which are non-specific, can be encountered in other neurological diseases such as amyotrophic lateral sclerosis and stroke as well as in normal controls. ${ }^{16-19303444}$ Zielasek et $a b^{35}$ who evaluated those techniques and others, only found discrepancies for negative or low titres. The fact that there are natural antibodies with low titres in normal controls, however, does not negate the effect of high titres in autoimmune diseases. ${ }^{45}$

All but five patients were treated by IVIg. Most of them improved initially, although only one third seemed to show a lasting response. Only one patient with amyotrophy who had an initial good response to IVIg treatment had a sustained response. The absence of amyotrophy therefore seemed to predict a good and prolonged response to IVIg treatment. The patients without amyotrophy, in our experience, did not develop muscle wasting during follow up. This finding seems to justify the separation of patients into two groups.

Among the patients treated, about two thirds with an initial good response to IVIg, whatever the subsequent responses, had high or significant anti-GM1 antibody titres, but 
less than half of the patients had high titres. Only $50 \%$ of the patients with an initial good and sustained response had high titres. A correlation between the presence of high titres of anti-GM1 antibodies and the long lasting response to IVIg cannot therefore be confirmed, but no follow up study of the antiGM1 antibody titre in relation to the patient's response was performed.

\section{CONCLUSION}

Two patterns of clinical presentation could be isolated-namely, patients with motor deficit without pronounced muscle wasting, with a good response to IVIg suggesting a demyelinating lesion on a motor nerve leading to a conduction block; and those with pronounced amyotrophy mimicking a spinal muscular atrophy with a predilection for upper limbs, and a lesser sensitivity to IVIg treatment. The homogeneity of the syndrome of multifocal motor neuropathy with persistent conduction blocks and underlying physiopathological mechanism is therefore uncertain. Although there was no obvious correlation between the long lasting response to IVIg treatment and the presence of high anti-GM1 antibody titres, further studies should be performed to detect antiglycolipid antibodies to other components of the nodes of Ranvier, and to evaluate the utility of the titres of these antibodies in determining the clinical response.

1 Lewis RA, Sumner AJ, Brown MJ, Asbury AK. Multifocal demyelinating neuropathy with persistent conduction block. Neurology 1982;32:958-64

2 Roth G, Rohr J, Magistris MR, Ochsner F. Motor neuropathy with proximal multifocal persistent conduction block, fasciculations and myokymia. Evolution to tetraplegia. Eur Neurol 1986;25:416-23.

3 Roth G, Magistris MR. Neuropathies with prolonged conduction block, single and grouped fasciculations, localized limb myokymia. Electroencephalogr Clin Neurophysiol 1987;67:428-38.

4 Parry GJ, Clarke S. Multifocal acquired demyelinating neuropathy masquerading as motor neuron disease.

5 Pestronk A, Cornblath DR, Ilyas AA, Baba $\mathrm{H}$, et al. A treatable multifocal motor neuropathy with antibodies to GM1 ganglioside. Ann Neurol 1988;24:73-8.

6 Auer RN, Bell RB, Lee MA. Neuropathy with onion bulb formations and pure motor manifestations. Can $\mathcal{f}$ Neurol Sci 1989;16:194-7.

7 Van den Bergh P, Logician EL, Kelly J. Motor neuropathy with multifocal conduction blocks. Muscle Nerve 1989;11:26-31.

8 Krarup C, Stewart JD, Sumner AJ, Pestronk A, Lipton SA. A syndrome of asymmetric limb weakness with motor conduction block. Neurology 1990;40:118-27.

9 Lange DJ, Trojaborg W, Latov N, et al. Multifocal motor neuropathy with conduction block: Is it a distinct clinical neuropathy with conduction block: Is
entity? Neurology 1992;42:497-505.

10 Adams D, Kuntzer T, Steck AJ, Lobrinus A, Janzer RC, Regli F. Motor conduction block and high titres of antiGM1 ganglioside antibodies: pathological evidence of a motor neuropathy in a patient with lower motor neuron
syndrome. F Neurol Neurosurg Psychiatry 1993;56:982-7.

11 Lange DJ, Trojaborg W, McDonald TD, Blake DM Persistent and transient "conduction block" in motor neuron diseases. Muscle Nerve 1993;16:896-903.

12 Chaudhry V, Corse AM, Cornblath DR, Kuncl RW, Freimer ML, Griffin JW. Multifocal motor neuropathy:
electrodiagnostic features. Muscle Nerve 1994;17: 198-205.

13 Freddo L, Yu RK, Latov N, et al. Gangliosides GM1 and GD1b are antigens for IgM M-protein in a patient with motor neuron disease. Neurology 1986;36:454-8.

14 Latov N, Hays AP, Donofrio PD, et al. Monoclonal IgM with unique specificity to gangliosides GM1 and GD1b with unique specificity to gangliosides GM1 and GDlb neuron disease. Neurology 1988;38:763-8.

15 Nardelli E, Steck AJ, Barkas T, Schluep M, Jerusalem F. Motor neuron syndrome and monoclonal IgM with antibeurol 1988;23:524-8.

16 Nobile-Orazio E, Carpo $M$, Legname G, Meucci $N$, Sonnino S, Scarlato G. Anti-GM1 IgM antibodies in motor neuron disease and neuropathy. Neurology 1990;
40:1747-50.
17 Sadiq SA, Thomas FP, Kilidireas K, et al. The spectrum of neurologic disease associated with anti-GM1 antibodies. Neurology 1990;40:1067-72.

18 Ben Younes-Chennoufi A, Meininger V, Léger JM, Bouche P, Jauberteau MO, Baumann N Antiganglioside antibodies in motor neuron diseases and peripheral neuropathies: study by ELISA technique and immunodetection on thin-layer chromatography. Neurochemistry International 1992;20:353-7.

19 Apostolski S, Latov N. Clinical syndromes associated with anti-GM1 antibodies. Sem in Neurology 1993;13:264-8.

20 Feldman EL, Bromberg MB, Albers JW, Pestronk A Immunosuppressive treatment in multifocal motor neuropathy. Ann Neurol 1991;30:397-401.

21 Kaji R, Shibasaki H, Kimura J. Multifocal demyelinating motor neuropathy: cranial nerve involvement and immunoglobulin therapy. Neurology 1992;42:506-9.

22 Chaudhry V, Corse AM, Cornblath DR, et al. Multifocal motor neuropathy: response to human immune globulin. Ann Neurol 1993;33:237-42.

23 Cruz Martinez A, Arpa J, Lara M. Electrophysiological improvement after intravenous immunoglobulin in motor neuropathy with multifocal conduction block. $f$ motor neuropathy with multifocal conduction
Neurol Neurosurg Psychiatry 1993;56:1236-7.

24 Nobile-Orazio E, Meucci N, Barbieri S, Carpo $M$, Scarlato G. High-dose intravenous immunoglobulin therapy in multifocal motor neuropathy. Neurology 1993; 43:537-44.

25 Tsai CP, Lin KP, Liao KK, et al. Immunosuppressive treatment in lower motor neuron syndrome with autoantibodies against GM1 ganglioside. Eur Neurol 1993; 33:446-9.

26 Tan E, Lynn J, Amato AA, Kissel JT, et al. Immunosuppressive treatment of motor neuron syndromes. Arch Neurol 1994;51:194-200.

27 Santoro M, Thomas FP, Fink ME, et al. IgM deposits at nodes of Ranvier in a patient with amyotrophic lateral sclerosis, anti-GM1 antibodies, and multifocal motor conduction block. Ann Neurol 1990;28:373-7.

28 Kaji R, Oka N, Tsuji T, et al. Pathological findings at the site of conduction block in multifocal motor neuropathy. Ann Neurol 1993;33:152-8.

29 Krendel DA, Costigan DA. Multifocal motor neuropathy or CIDP? Ann Neurol 1993;34:750.

30 Steck AJ, Adams D. Motor neuron syndromes and monoclonal IgM antibodies to gangliosides. In: Roland LP, ed. Advances in neurology. Vol 56: amyotrophic lateral sclerosis and other motor neuron diseases. New York: Raven Press, 1991:421-5.

31 Sumner AJ. Separating motor neuron diseases from pure motor neuropathies. Multifocal motor neuropathy with persistent conduction block. In: Roland LP, ed. Advances in neurology. Vol 56: amyotrophic lateral sclerosis and other motor neuron diseases. New York: Raven Press, 1991:399-403.

32 Parry GJ, Sumner AJ. Multifocal motor neuropathy. In: Dyck PJ, ed. Peripheral neuropathy: new concepts and treatments. Neurologic clinics, Philadelphia: WB Saunders Co, 1992:671-84

33 Serratrice G. Neuropathies motrices avec anticorps antiglycolipides. La Presse Médicale 1993;22:705-7.

34 Adams D, Kuntzer T, Burger D, et al. Predictive value of anti-GMl ganglioside antibodies in neuromuscular diseases: a study of 180 sera. $\mathcal{F}$ Neuroimmunol 1991;32: 223-30.

35 Zielasek J, Ritter G, Magi S, Hartung HP, Toyka KV and participating laboratories. A comparative trial of antiglycoconjugate antibody assays: IgM antibodies to GM1. I Neurol 1994;241:475-80.

36 Mailly P, Ben Younes-Chennoufi A, Bon S. The monoclonal antibodies Elec-39, HNK-1 and NC-1 recognize common structures in the nervous system and muscles of vertebrates. Neurochemistry International 1989;15: of verte

37 Rhee EK, England JD, Sumner AJ. A computer simulation of conduction block: effects produced by actual block versus interphase cancellation. Ann Neurol 1990;28: $146-56$

38 Cornblath DR, Kuncl RW, Mellits ED, et al. Nerve conduction studies in amyotrophic lateral sclerosis. Muscle Nerve 1992;15:1111-5.

39 Magistris MR, Roth G. Motor axon reflex and indirect double discharge: ephaptic transmission? A reappraisal. Electroencephalogr Clin Neurophysiol 1992;85:124-30.

40 Sahenk Z, Tan E, Kissel JT, Lynn J, Barohn RJ, Mendell JR. Immunosuppressive treatment in motor neuron syndromes: sural nerve biopsy findings. Neurology 1993; 43(suppl 4):258.

41 Shefner JM, Tyler HR, Krarup C. Abnormalities in the sensory action potential in patients with amyotrophic latsensory action potential in patients with amyotr
eral sclerosis. Muscle Nerve 1991;14:1242-5.

42 Mondelli M, Rossi A, Passero S, Guazzi GC. Involvement of peripheral sensory fibers in amyotrophic lateral sclerosis: electrophysiological study of 64 cases. Muscle Nerve 1993;16:166-72.

43 Pestronk A. Motor neuropathies, motor neuron disorders, and antiglycolipid antibodies. Muscle Nerve 1991;14 927-36.

44 Lamb NL, Patten BM. Clinical correlations of anti-GM antibodies in amyotrophic lateral sclerosis and neuropathies. Muscle Nerve 1991;14:1021-7.

45 Avrameas $S$, Ternynck $T$. The natural autoantibodies system: between hypotheses and facts. Mol Immunol 1993 30:1133-42. 